\title{
Relación y memoria sumaria de lo acontecido en Bayona y Vigo por el ataque de Francis Drake el año de 1585
}

\section{Report and Summary Memory of What Happened in Bayonne and Vigo because of the Attack by Francis Drake in 1585}

\author{
Jenaro Costas Rodríguez \\ Universidad Nacional de Educación a Distancia \\ jcostas@flog.uned.es
}

Resumen: En el artículo se ofrece la transcripción de una relación o informe sobre un hecho histórico: el ataque de una flota inglesa capitaneada por Francis Drake a los puertos de Bayona y Vigo el año 1585. En él se estudian las peculiaridades de este relato y se compara con otras fuentes escritas sobre el mismo hecho resaltando las divergencias que hay entre ellos. El texto se encuentra en el Ms. 5938 de la BNE en un códice de varios y se publica aquí por primera vez.

Palabras clave: Historia de España. Historia de Inglaterra. Historia de Bayona. Historia de Vigo. Francis Drake. Felipe II. Corsarios.

Summary: The article offers the transcription of a paper or report on a historical event: the attack of an English fleet led by Francis Drake on the ports of Bayonne and Vigo in 1585. It studies the peculiarities of this account and includes a comparative analysis with other existing sources on the same event, highlighting the differences. The text that is published here for the first time belongs to the Ms. 5938, a codex of various issues found at the National Library of Spain.

Key words: History of Spain. England history. Bayonne history. Vigo history. Francis Drake. Felipe II. Corsairs. 


\section{LA RELACIÓN HISTÓRICA}

El tipo de escrito que vamos a estudiar en este trabajo forma parte de un género que Miguélez denomina «relaciones históricas» y define de este modo:

Entiéndese por relación histórica el relato más o menos breve de cualquier suceso importante que pueda dar luz a la historia en general. Será, por tanto, relación histórica un documento diplomático o cancilleresco, carta, noticia, episodio, acontecimiento, descripción geográfica o topográfica, diario de viaje, parte, aviso, declaración de guerra, tratado de paz o de alianza. (Miguélez 1917: VIII, vol. I).

Estos escritos eran redactados por diversos personajes, algunos de relevancia, que dejaban constancia de su autoría, pero otros muchos, como el que aquí presentamos, quedaban en el anonimato. Suponemos que los cronistas oficiales del reino tenían una red de corresponsales fijos o eventuales, que le proporcionaban estos informes, celosamente guardados por ellos para su posterior utilización al elaborar sus crónicas.

En este caso se trata de un informe que debe haber pasado por distintas manos desde Florián de Ocampo hasta Ambrosio de Morales y actualmente consta en el Ms. 5938 (ff. 423-428) de la Biblioteca Nacional de España y así se le menciona en el Inventario general de manuscritos de la Biblioteca Nacional, vol. II, p. 62: 56 (ff. 423-428) Relación de lo acontecido en Bayona en 1585 por el ataque de Francisco Draque. Se trata de un Códice de Varios, copiado del de la Biblioteca del Escorial que fue de Ambrosio de Morales. Tiene un total de 64 documentos y 476 folios y es una muestra genuina del tipo de escritos que estamos comentando. El escrito está encabezado por este título: Relación y memoria sumaria de lo acontecido en Vayona este año de 1585.

En la transcripción del documento nos hemos permitido algunas licencias con la finalidad exclusiva de facilitar su lectura a todo interesado posible. Por ello, queremos hacer estas indicaciones: a) mantenemos la ortografía del manuscrito, no acorde con la actual en muchos casos, así como las mayúsculas, a veces innecesarias; b) hemos adaptado a los criterios actuales todo lo referente a acentuación de las palabras y puntuación de los distintos párrafos; c) hemos corregido los que consideramos errores de copia señalándolos unas veces con paréntesis angulares $(<>)$ y otras en notas a pie de página; d) hemos resuelto las pocas abreviaturas que contenía; e) en la división de palabras hemos seguido el criterio práctico de evitar ambigüedades posibles.

Desde el punto de vista lingüístico está redactado en un castellano bastante correcto, en el que no se perciben interferencias de otras lenguas o peculiaridades locales. No podemos saber si en las posibles transcripciones que sufrió se han alterado algunos rasgos lingüísticos propios o no.

El tema me pareció adecuado para homenajear al Profesor Manuel Rodríguez Alonso, que tan buen recuerdo ha dejado en nuestro Departamento y Universidad por su calidad humana, científica y universitaria y a él va dedicado en agradecimiento por su valiosa aportación a la filología gallega. 
Pero antes de entrar en materia creemos conveniente hacer algunas reflexiones que contextualicen los hechos que narra nuestro documento.

El contexto político venía precedido de lo que algún historiador (LLOYD 1958: 98) califica de «guerra fría» o quizá podíamos denominar «guerra larvada» entre la Inglaterra de Isabel I y la España de Felipe II. Dos hechos son los que al parecer provocan el salto a la guerra abierta de facto: la orden de Felipe II de incautar todos los barcos ingleses surtos en puertos españoles (Lloyd 1958: 98) y la toma de Amberes, pues en 1585 Isabel I había decidido reconocer la independencia de los Países Bajos y convertirse en su aliado y protector. En Inglaterra se decide organizar una flota de guerra con este objetivo: atacar las colonias españolas, interrumpir su comercio e idealmente interceptar la flota anual del tesoro (Konstan 2011: 31). Con ello intentaban mermar la capacidad militar del imperio español y debilitar sus recursos económicos. La excusa diplomática que se daría a la opinión internacional era la liberación de los barcos ingleses incautados por España.

La expedición se organizó como una «empresa de inversión», en el sentido de que cada accionista aportaba una determinada cantidad en dinero y medios (barcos) y se esperaba recuperar la parte correspondiente de acuerdo con las ganancias obtenidas. Los nombres de los accionistas no se hicieron públicos, pero se sabe de los principales: Isabel I aportó 10.000 libras y el buque de mayor tonelaje, Isabel Buenaventura, que Drake utilizó como nave capitana y otro de menor tonelaje. También participaron en el negocio algunos nobles y comerciantes ingleses, así como el propio Drake (Konstan 2011: 28). Este personaje, Francis Drake, conocido y experimentado marino y corsario, fue elegido jefe de la expedición, acompañado de otros marinos expertos y generales de prestigio.

El Almirante Drake desconfiaba de la determinación de la reina y sus asesores en seguir adelante con la empresa, que se estaba organizando en Plymouth, y para evitar cualquier contraorden salió precipitadamente del puerto sin completar el avituallamiento de sus naves y sin resolver otros asuntos de organización de la flota, evitando incluso los puertos ingleses para eludir cualquier posibilidad de contraorden de la reina (Konstan 2011:32). Ese parece ser el motivo de su entrada en la ría de Bayona y Vigo (González 1970: 288). De hecho, la necesidad de avituallarse de agua y bastimentos es una de las razones que esgrimen ante las autoridades españolas, a la que agregan la excusa «tapadera» de la liberación de los buques ingleses. Por otro lado, parece haber unanimidad entre historiadores en la opinión de que el tiempo perdido en Bayona y Vigo impidió el logro de uno de los objetivos de la expedición: el saqueo de la flota del tesoro español de las Indias Occidentales, circunstancia por la que tuvo que rendir cuentas Drake ante las autoridades y los accionistas de la empresa.

Debemos advertir que, aunque hemos manejado una amplia bibliografía, no hemos pretendido la exhaustividad, ni esa es la intención de este trabajo. Como nuestra finalidad primera era publicar este relato, que nos pareció interesante dar a conocer al público estudioso en general, hemos procurado rehuir toda crítica o suscitar cualquier tipo de polémica con otras publicaciones sobre el 
tema. Nos limitamos a señalar las divergencias sin emitir juicios ni valoraciones sobre las mismas. Que el lector saque sus propias conclusiones. ${ }^{1}$

Como complemento de la mera transcripción hemos elaborado los siguientes apartados para facilitar su análisis: a) un listado de los personajes que intervienen en el relato o en los comentarios al mismo; b) una sinopsis del contenido con notas y citas de otros autores para poner de manifiesto las divergencias entre ellos; c) en último lugar dedicamos una sección a resaltar los aspectos que nos parecen novedosos en la Relación frente a los demás testimonios consultados.

\section{PERSONAJES MENCIONADOS EN ESTE TRABAJO}

a) Ingleses:

- Francis Drake: corsario famoso, Almirante de la flota y jefe de la expedición inglesa.

- Martin Frobisher: Vicealmirante de la flota inglesa, marino famoso por los viajes en busca del paso del Noroeste, interesado en el pillaje y combate.

- Cristopher Carleill: ${ }^{2}$ general inglés de gran experiencia en Irlanda y Países Bajos; estaba al mando de las tropas terrestres.

- Sampson: capitán, Ayudante de Campo de Carleill, enviado a parlamentar con Bermúdez el primer día y después como rehén a Bayona.

- Crosse: capitán enviado a Bayona como rehén.

- Erisey y Crosse: capitanes enviados para garantía de la entrevista de Bermúdez con Drake.

- Walter Biggs: formaba parte de la expedición de Drake e iba bajo el mando del general Carleill; escribió un relato de la expedición.

\section{b) Españoles:}

- Pedro Bermúdez de Santiso: capitán por su Majestad y gobernador de la villa de Bayona.

- Diego Sarmiento de Acuña: señor de Gondomar y Vincios.

\footnotetext{
${ }^{1}$ Quiero agradecer a mi amigo Gonzalo Gómez González la gran ayuda que me prestó proporcionándome valiosa bibliografía cuando comencé a pensar en este trabajo. El relato me resultó atractivo por el recuerdo de nuestros incansables paseos, en nuestra juventud, por los mismos parajes por donde se desarrollaron los hechos que aquí se narran.

2 Emilio González López (1970: 288) dice que los historiadores ingleses se basan en los relatos de Biggs y de Carleill, que formaban parte de la expedición, para dar una versión totalmente distinta a la española.
} 
- García Sarmiento: señor de Salvatierra. ${ }^{3}$

- Juan Maldonado: capitán de Bayona, natural de Salamanca.

- Diego de Córdova: capitán de Caminha, que acudió con su compañía a Bayona.

- Gonzalo Raxo de Acuña: capitán al mando de los 300 hombres enviados por Diego Sarmiento.

- Bartolomé de Molino: Obispo de Tuy.

- Lope García Sarmiento: Chantre de Tuy.

- Juan Saravia: Tesorero de Tuy.

- Manuel Pereyra: Canónigo de Tuy.

- Antonio Ruiz de Guaza: alguacil de la gente de guerra, enviado por Bermúdez a parlamentar con Drake el primer día.

- Roberto Skarte: comerciante inglés que acompañaba a Ruiz de Guaza.

- Gabriel de Quirós y Sotomayor: entregado como rehén a Drake.

- Juan Sarmiento: entregado como rehén a Drake.

- Martín Aragonés: administrador; personaje del séquito de Bermúdez en su entrevista con Drake.

- Benito de Barros: personaje del séquito de Bermúdez en su entrevista con Drake.

- Pedro Ortiz de Écija: personaje del séquito de Bermúdez en su entrevista con Drake. ${ }^{4}$

- Diego Sarmiento: personaje del séquito de Bermúdez en su entrevista con Drake.

\section{SINOPSIS DEL CONTENIDO}

Día 7 de octubre: ${ }^{5}$

\footnotetext{
3 La familia García Sarmiento había sido beneficiada al haber apoyado a Isabel la Católica frente a Juana la Beltraneja. Éste era hijo de Juan Sarmiento de Soutomaior, señor de Salvaterra y O Sobroso. Primo hermano de Diego Sarmiento de Acuña, con quien casó su hija Beatriz.

4 Ramos (1925: 71) menciona a Pedro Ruiz de Ayala como uno de los regidores de Bayona. Ignoramos si puede tratarse de la misma persona con error en el segundo apellido.

5 La Relación, al igual que la mayoría de los historiadores hispanos, datan la llegada el día 7 de octubre, mientras que los historiadores ingleses la fechan el 27 de septiembre. Ello se debe a que los unos utilizan el calendario gregoriano, mientras que en Inglaterra, Gales, Irlanda, y las colonias británicas continuó utilizándose el calendario juliano hasta 1752. La reforma de Gregorio XIII decretaba que el jueves 4 de octubre de 1582 sería seguido del viernes 15 de octubre para
} 
Llega la flota enemiga

arriba a las islas de Bayona (Islas Cíes) ${ }^{6}$

Efectivos de la armada enemiga:

28 naos gruesas ${ }^{7}$

Desembarco de una tropa inglesa:

la misma noche a las 8 horas, con 24 lanchas, al arrabal de Nuestra Señora del Burgo, con mil quinientos hombres $(1.500)^{8}$

-Pedro Bermúdez de Santiso, capitán por S. M. en aquella villa se recogió con 150 soldados en Monte Real ${ }^{9}$

-Bermúdez envió un hidalgo con dos compañeros y un inglés de los que tratan en este reino con bandera de paz ${ }^{10}$

-embajada: le suplicaba que viniese a la villa a recibir algún servicio y regalo

-embajada de Drake: envía un capitán suyo con bandera de paz ${ }^{11}$

contenido: venía por orden de la reina de Inglaterra

para deshacer lo que el rey había hecho a los ingleses (aprisionado y tomado sus haciendas)

pedía que se los entregase libremente

de lo contrario, con 50 naos gruesas que traía asolaría la villa

-respuesta de Bermúdez:

compensar la diferencia acumulada a lo largo de los siglos en el calendario juliano. De ahí proceden las diferencias de datación en este caso, que son de unos diez días.

${ }^{6}$ Es curioso que se les mencione siempre con el genérico «islas de Bayona» sin nombre propio alguno.

7 No todos los autores consultados coinciden en el número de barcos de la flota corsaria: Fernández (2008: 98): 11 naos grandes, 8 menores y buques de aprovisionamiento: total cerca de 30 naves; González (1970: 286): 21 barcos, 8 pinazas; Ramos (1925: 72): 30 naves de guerra; Álvarez (2008: 427): 19 naves de gran y mediano porte y algunos pataches; Corbett (1970: 1): 29 naves y pinazas; Konstan (2011: 30): 29 naves de diversos tamaños desde el Buenaventura hasta pequeñas pinazas de 20 toneladas.

${ }^{8}$ Hay bastante discrepancia entre los diversos autores sobre el número de soldados desembarcados esa tarde: Fernández (2008: 98): 1.500 hombres; González (1970: 288): con pinazas y 700 hombres al mando de Carleill; Ramos (1925: 69): 28 lanchas y 1.500 soldados; Álvarez (2008: 427): 1.500 soldados; Corbett (1970: 2): 200 hombres; Harry (2002: 303): un grupo de 700 soldados; Keeler (1981: 78): desembarcaron 1.000 hombres.

9 Algunos elevan ligeramente el número de soldados defensores de la fortaleza: Fernández (2008: 98): 200 hombres; Ramos (1925: 71): en la fortaleza no había más de 200 hombres.

${ }_{10}$ Ramos (1925: 69) precisa sus nombres: Antonio Ruiz de Guaza y el inglés Roberto Skarte.

${ }_{11}$ El elegido fue el capitán Sampson «por su particular habilidad y juicio y para que tomase especial información del lugar y la gente» (Keeler 1981: 79). 
los ingleses ni estaban presos ni tomadas sus haciendas, sino que andaban libremente

no podía creer que viniese con semejante demanda de la reina

le suplicaba otra vez a recibir servicio y regalo de la villa

si determinaba seguir, defendería la fuerza con dos mil hombres que tenía queriendo replicar el mensajero, el capitán le ordenó irse, si no quería que le colgase de una almena

-una tormenta obliga a los ingleses a replegarse a su armada:

queman una imagen muy antigua de Nuestra Señora y otras imágenes en la ermita del Burgo y queman una casa

con la prisa quedan sin embarcar dos mancebos ingleses, que por la mañana hallaron entre unas peñas y los llevaron a Bermúdez

-Bermúdez da aviso al obispo de Tuy, y a los demás señores y lugares cercanos, para que le favoreciesen con gente y bastimentos

avisa también a S. M. y al Cardenal, ${ }^{12}$ que estaba en Lisboa

-Acuden entre el 8-10 de octubre muy cerca de 5.000 hombres:

Diego de Córdoba, capitán de S. M. en Camiña, lugar de Portugal, con 140 mosqueteros y arcabuceros

Bartolomé de Molino, obispo de Tuy, envió 400 hombres

Diego [Sarmiento] de Acuña, yerno de D. García Sarmiento, señor de Salvatierra, al mando de 1.500 arcabuceros y piqueros

los demás se descolgaron de aquellas sierras y lugares

dióse orden a 100 vecinos el día 9 de alojar a aquella gente

-Están vigilantes por lo que pueda hacer el enemigo:

nuestro capitán Bermúdez.

Don Diego de Córdoba

Don Juan Maldonado, capitán por S.M. en aquella villa, natural de Salamanca

\section{Día 9 miércoles:}

-movimiento de la armada de Drake el miércoles 9 a la noche:

los ingleses se retiran a la ría de Bouzas y Vigo, por temor al mal tiempo, con 27 naos y dejando por espía una nao en las islas

12 El Archiduque Alberto de Austria: fue nombrado virrey de Portugal (desde el año de 1583 hasta el año de 1594); arzobispo de Toledo sustituyendo al fallecido Gaspar de Quiroga en 1594. 


\section{Día 10 de octubre jueves:}

-movimiento de Bermúdez:

el 10 de octubre a las 10 de la noche sale de Bayona acompañado de:

Diego de Córdoba, con su compañía de 140 hombres

400 hombres de García Sarmiento

la gente del obispo de Tuy (400 hombres)

antes de amanecer llegan al cabo de Teis donde estaba la armada enemiga

-escaramuzas del jueves:

el enemigo salta en cuatro lanchas con un número ${ }^{13}$ de gente para robar ganado vacuno del valle de Teis

treinta arcabuceros de Diego de Córdoba escaramuzan con ellos

desde la armada enemiga envían socorro y lanchas

los nuestros mataron a dos

uno de los nuestros cortó la cabeza a un inglés

los enemigos entraron en la iglesia, quemaron la imagen de San Salvador y llevaron la campana

-el miércoles anterior los enemigos tomaron al pasar por Vigo un barco que allí estaba desde tres días con la riqueza de la iglesia de aquella villa, estimada en 5.000 escudos y algunos dicen que mucho más ${ }^{14}$

\section{Día viernes 11:}

-posición de las tropas:

toda el armada enemiga en el puerto de Teis

Bermúdez en Vigo con toda su gente, que serían cinco mil hombres

-movimientos:

a las dos de la noche se embarcan sin ser sentidos en una montañeta frontero del enemigo 180 arcabuceros de las compañías de Diego de Córdoba y García Sarmiento

\section{Día sábado 12:}

-movimiento de la tropa de Bermúdez:

13 González (1970: 290) citando a Corbett dice «que Drake ordenó a Carleill desembarcar con un grupo de 80 hombres».

14 Cfr. Corbett (1970: 4): «el valor de una de las cruces era de 3.000 ducados; la otra cruz, dinero, plata, joyas y pieles se evaluó en 3.000 ducados». 
Bermúdez sale de Vigo acompañado de muchas personas principales forma escuadrón arriba en el monte deja abajo en El arenal seis banderas formadas al mando del capitán Juan Maldonado

él se pone a la orilla del puerto, donde estaba la armada, acompañado por: Diego de Acuña; Diego Sarmiento; Benito de Varros; Lope García Sarmiento, chantre de Tuy; Juan Saravia, tesorero de Tuy; Manuel Pereira, canónigo y otros muchos caballeros de la tierra

envía recaudo al enemigo para parlamentar

vino una lancha de la armada a donde estaba Bermúdez

se embarca con todos los dichos y se aproxima a la armada

sale de la capitana el enemigo con otra lancha

cuando se juntaron ambas, el enemigo solicitó hablar a solas con nuestro capitán y le rogó que pasase a su lancha

así lo hizo junto con el dicho tesorero, y Pedro Ortiz de Écija y el administrador Martín Aragonés

los dos capitanes hablaron solos

-Acuerdos adoptados por ambas partes:

Francisco Drake devolvería todo lo que había tomado:

la plata y ornamentos de Vigo

todo lo demás que está dicho

-respecto a la restitución a la reina de Inglaterra de sus vasallos y haciendas:

no se podía hacer sin orden de S.M.

entretanto no haría daño con su armada en este puerto

-se dieron rehenes:

de nuestra parte los caballeros:

Gabriel de Quirós y Sotomayor y Juan Sarmiento

de parte del enemigo:

dos hombres al parecer honrados, uno viejo y otro mozo ${ }^{15}$

-se deshizo el campo y salieron los de la emboscada y se fueron a sus casas los de la tierra

15 Los capitanes Crosse y Sampson (Corbett 1970: 4). 


\section{Día Domingo 13:}

Bermúdez se fue a Bayona con los rehenes

-Intento de saqueo a Redondela:

salen de la armada dos o tres lanchas con 150 hombres para saquear Redondela

al saberlo huyen los de la villa y las monjas que hay allí

al entrar en la villa encallaron las lanchas por la marea baja y se dieron la vuelta

-Asalto a la isla de San Simón al volver de Redondela:

había solo un monasterio con seis frailes franciscanos, que se metieron en un barco y lograron escapar pese a los escopetazos del enemigo

los enemigos se fueron al monasterio, rompieron la campana y la llevaron con otras cosas

\section{Día 15:}

el enemigo tomó junto a Vigo una «nao de vacallao», no cumpliendo lo que se había trazado

-Reacción de Bermúdez:

envía a decir por medio de Juan Maldonado que devuelva la riqueza de Vigo y las naos que había tomado

-Respuesta del enemigo:

prendió a Juan Maldonado y a los que con él iban

-Medidas de Bermúdez:

tornó a mandar que volviese la gente y así se hizo

\section{Día 17:}

el enemigo sale del puerto de Teis con Maldonado preso y se dirige a las islas de Bayona

nuestro capitán repartió la gente por estancias para la defensa

\section{Día 19:}

el enemigo tomó a la boca de las islas dos naos que venían de Brasil

el enemigo envió los presos y los rehenes que tenía a nuestro capitán

Bermúdez le envió los rehenes que tenía ${ }^{16}$

16 Corbett (1970: 5) da una versión más precisa del fin de la negociación: «el día 8 preparamos tres pinazas, una galera y el navío George y los enviamos a Bayona, donde después de mucho parlamento recibimos a nuestros capitanes y les entregamos sus hombres». 


\section{Día 21:}

alzó velas el enemigo y se fue no se sabe a dónde ${ }^{17}$

la gente se volvió a sus casas

se quedan en Bayona con Bermúdez las capitanías de soldados viejos

S.M. hizo a Bermúdez capitán a guerra y le envió título.

\section{Finis.}

\section{RELACIÓN Y MEMORIA SUMARIA DE LO ACONTECIDO EN VAYONA ESTE AÑO DE 1585}

[fol. 423r]

A siete de Octubre llegó Francisco Draques, cosario ynglés, con 28 naos gruesas a las islas de Vayona, puerto de mar, 18 leguas de Orense, ${ }^{18}$ dos leguas de las mismas yslas. Y aún no era bien sabida su venida, quando la mesma noche, a las 8 horas, con 24 Lanchas llegó a nuestra Señora del Vurgo, ${ }^{19}$ ques como arrabal de la misma Villa, y echó en tierra mil y quinientos hombres. Luego fue sabido por Pedro Vermudes de Santiso, Capitán por S. M. en aquella Villa, el qual había seis días que era llegado allí desde Lisboa con orden de S. M., y a la hora se recogió con ciento y cincuenta Soldados [fol. 423v] que tenía dentro de la Villa que se llama Monte Real, dejando desamparado el Arrabal y Pescadería, que es muy mayor que la misma Villa, porque la gente que la habitaba, unos huyeron, y otros se recojieron con el Capitán.

Pedro Vermudes embió un Hidalgo ${ }^{20}$ con dos compañeros, y un inglés ${ }^{21}$ de los que tratan en este Reyno, con vandera de paz al ynglés, diciendo que él había sabido que su $\mathrm{m}<$ erce $>\mathrm{d}$ estaba en aquel puerto, que le suplicaba se viniese a la Villa a recibir algún servicio y regalo. El Francisco Draques replicó que Vermudes no estaba allí, y certificado dello por el ynglés que iba en compañía de nuestro embaxador, preguntó quanta gente tenía, y se le respondió que ducientos y cincuenta soldados: replicó que no era posible tener más de ciento, y con esto los embió.

Luego Draques embió un Capitán suyo con bandera de paz a Pedro Vermudes diciendo: que él había venido por mandado de la Serenisima Reyna de Yngalaterra, su Señora, sobre aquella fuerza de Vayona, y a desacer la que S. M. del (sic) Rey nuestro Señor había hecho a los ingleses en los haber [fol. 424r] aprisionado y tomado sus haciendas; que le pedía luego se los entregase libre-

17 Cfr. Harry (2002: 307): «en la mañana del 11 de octubre se levantó un viento propicio para la navegación con el que los piratas se hicieron a la mar».

18 Orence (en el ms.)

19 «Donde es hoy Santa Marta» (cfr. Ramos 1925: 70).

20 Llamado Antonio Ruiz de Guaza, según Ramos (i 925: 69).

21 Llamado Roberto Skarte, según Ramos (i925: 69). 
mente, y si no, que con cincuenta naos gruesas que traía, asolaria y echaria por tierra aquella Villa y puerto. Replicóse por Pedro Vermudes que S. M. no había hecho ninguna fuerza ni agravio a los ingleses, ni estaban presos ni tomadas sus haciendas, antes andaban libres cobrándolas y beneficiándolas, como ellos lo podían decir; y que siendo esto notorio y la Reyna inglesa hermana de S. M. no podía creer que viniese con semejante demanda; que le suplicaba otra ves viniese a aquella Villa a recibir servicio y regalo, y que si todavía se determinaba en seguir el propósito declarado, le hacía saber que él era uno de los menores Capitanes que tenía S. M.: mas con todo eso estaba defendiendo aquella fuerza con dos mil hombres, con los quales y su justicia, y con defender la fee y honra de Dios, esperaba en su divina Magestad defendella de todo el poder del mundo; y queriendo replicar, el Capitán le mandó que no hablase más y se fuese, si no quería que le hiciese colgar de una almena.

Vuelto el inglés a su Capitán con este recado, hacía [fol 424v] tan áspera y braba tormenta con ayre, agua y escuridad que no teniéndose por seguro el inglés acordó volverse a su armada y naos que, como digo, estaban dos leguas de allí; y lo hicieron dejando quemada una imagen muy antigua de Nuestra Señora, y otras imágenes, y quemada una casa, y con la priesa se quedaron sin poder embarcar dos mancebos ingleses, los quales fueron hallados por la mañana entre unas peñas, y los llebaron a Pedro Bermudes: tiénese por milagro la tempestad de aquella noche, porque a no hacella, robaran, quemaran, y asolaran a la Villa vieja de Vayona sin ninguna resistencia, porque no la había.

Luego nuestro Capitán dio aviso al Señor Obispo de Tuy, que andaba media legua de allí visitando, ${ }^{22}$ y a los demás Señores y Lugares cercanos, para que le faboreciesen con gente y bastimentos para ella, y por otra parte a S. M. ${ }^{23}$ y al Señor Cardenal que estaba en Lisboa $^{24}$.

Al aviso y orden de Vermúdez acudieron a Vayona a 8 y 9 de Octubre, y a 10 muy cerca de cinco mil hombres: Don Diego de Córdova, Capitán de S. M. en Camiña, Lugar de Portugal, fue con su Comp[añía] [fol. 425r] de ciento y quarenta mosqueteros y arcabuceros; el Señor Obispo de Tui, Don Bartolomé de Molino, ${ }^{25}$ imbió quatrocientos, Don Diego de Acuña, yerno de Don García Sarmiento, Señor de Salvatierra, mil y quinientos hombres arcabuceros y piqueros muy en orden; los demás se descolgaron de aquellas Sierras y Lugares; a cien vecinos diose orden a 9 de alojar y repartir por aquellas Aldeas y Lugares toda esta gente. Y nuestro Capitán con Don Diego de Córdova, y Don Juan Maldonado, Capitán por S. M. en aquella Villa, natural de Salamanca, se

22 Visantando (en el ms.). Entendemos que es un error del copista por «visitando», término empleado para referirse a ciertos viajes de los obispos, como en el siguiente ejemplo sacado de CORDE: «Para mientes en la estoria del bien auenturado Sant Martin, obispo, e fallaras y que vna vegada andando visitando su obispado quiso visitar vna abadesa de vn monesterio de duennas» (1293, Anónimo, Castigos e documentos para bien vivir ordenados por el rey Sancho IV).

23 Fernández (2008: 100) reproduce algunas de las cartas enviadas por Bermúdez.

${ }^{24}$ El cardenal Archiduque Alberto de Austria, sobrino de Felipe II, virrey de Portugal (15831594).

25 Bartolomé Molino fue obispo de Tuy (1585-1589). 
estubieron a la mira de lo que el enemigo pretendía hacer, sin descuidarse solo un punto, antes con ánimo y deseo de venir a las manos con el enemigo.

La Armada enemiga, temiendo algún revés causado por el bravosísimo tiempo y tempestad que hacía, acordó acojerse, como lo hizo, a la Ría de Bouzas y Vigo, que está tres leguas de Vayona, con 27 naos, y otra que tomaron de Aceytes que había llegado de Sevilla, dejando una en las islas por espía y atalaya: esto fue miércoles 9 a la noche.

Juebes 10 de Octubre, sabido por nuestro Capitán lo dicho, a las 10 de la noche salió de Vayona [fol. 425v] y en su compañía Don Diego de Córdova con su compañía de ciento y quarenta mosqueteros y arcabuceros, y con quatrocientos arcabuceros de las compañías y gente de Don García Sarmiento, y con la gente del Obispo de Tuy, toda escojida. Y antes que amanesciese llegaron a Vigo, que son tres leguas, y en muy buena orden comenzaron a caminar acia la armada enemiga, que estaba en el Cabrón ${ }^{26}$ de Teis.

Este mesmo día Juebes sabiendo los enemigos que en aquel valle de Teis había ganado bacuno, con cuatro lanchas saltaron en tierra algún número de gente para llebarlas. Sabido por algunos de los de nuestro campo, se desgarraron dél por orden del Capitán treinta arcabuceros, soldados viejos de la compañía de Don Diego de Córdova, y viendo los enemigos comenzaron a escaramuzar con ellos, de tal manera que de la armada embiaron socorro y lanchas. Mataron los nuestros dos, y un soldado de los nuestros, viéndose con uno rostro a rostro, encararon los arcabuces y no tomaron lumbre, y con las espadas se afirmaron, y el nuestro pasó de una estocada a su contrario, y con el cuchillo de [fol. 426r] la vayna se puso encima dél, y le cortó la cabeza; y estándosela cortando, los enemigos de las lanchas le tiraron al nuestro muchos cañonazos, mas plugo a Dios que no le acertaron, y en la punta del cuchillo trajo la cabeza a Vigo, y el Capitán le señaló de ventaja seis escudos. Los enemigos entraron en la yglesia, y quemaron la imagen de San Salvador, y llebaron la campana.

Pasando el miércoles por Vigo el enemigo con su armada, tomó un barco que allí estaba había tres dias con la riqueza de la iglesia de aquella Villa; estimóse en cinco mil escudos, y otros dicen mucho más.

Estando junta la armada enemiga en el puerto de Teis, y nuestro Capitán en Vigo con toda su gente, que serían cinco mil hombres bien puestos, se dio orden de componerlos; y a once del presente, ya a las dos de la noche, a la orilla del mar en una montañeta frontera del enemigo, sin ser sentidos se embarcaron ciento y ochenta arcabuceros y mosqueteros de la compañía de Don Diego de Córdova, y de la gente de Don García Sarmiento.

26 «Cabrón de Teis»: agradezco a Francisco Costas Rodríguez, que tiene mejor memoria que la mía, el haberme advertido que «Cabrón» es el nombre de un peñasco o islote que hay junto al monte de La Guía (paraje por el que hicimos algunas correrías siendo bastante jóvenes), y no se trataba, como en principio yo pensé, de un error de copista por «cabo» o algo similar. 
El sábado siguiente 12 salió Vermúdez [fol. 426v] acompañado de muchas personas principales de Vigo, y después de haber formado esc $<$ u $>$ adrón arriva en el monte, y dejando abajo en el arenal seis vanderas en orden, mandó al Capitán Don Juan Maldonado se quedase con el Campo formado, y él con Don Diego de Acuña, ${ }^{27}$ y Diego Sarmiento, Benito de Varros, y Don Lope García Sarmiento, Chantre de Tuy, (margen: y Dn. Juan Saravia, Tesorero de Tuy) y el Canónigo Manuel Pereyra, y otros muchos Caballeros de la tierra, se puso a la orilla del puerto, donde estaba la armada. Luego imbió recaudo al enemigo diciendo que él estaba allí, y que quería saber dél qué era lo que pretendía o quería más de lo que había dicho. Y a esto vino una lancha de la armada a donde estaba Pedro Vermúdez, y lo que resultó fue que Pedro Vermúdez se embarcó en la dicha lancha (margen: con todos los otros y muy poco a poco se fue acia la armada. A esta sazón salió de la Capitana el enemigo en otra lancha,) y muy poco a poco se vino acia donde estaba la de nuestro Capitán, y poco lejos de la armada se juntaron las dos lanchas y se hablaron. Y porque el enemigo dijo que quería hablar con nuestro Capitán a solas sin testigos, le rogó se pasase a su lancha, y ansí lo hizo juntamente con el dicho Tesorero, y Pedro Ortiz de Écija, y el Administrador Martín Aragonés, y los [fol. 427r] dos Capitanes hablaron solos.

Lo que resultó fue que el Francisco Draquez había de volver todo lo que había tomado, que era la plata y ornamentos de Vigo, y todo lo demás que está dicho, y que en lo que él pretendía de que se restituyese a la Reyna de Ingalaterra sus vasallos y haciendas, que pues aquello no se podía hacer sin orden de S. M., que en el entretanto que se le diese $\mathrm{p}<$ arte $>$ y escribiese a la Reyna de Yngalaterra, no haría daño con su armada en este puerto ni Reyno. Y acabada esta resolución se dieron rehenes: de nuestra parte, se dieron dos Caballeros que fueron Don Gabriel de Quirós y Sotomayor, y Juan Sarmiento; y por el enemigo, se entregaron dos hombres al parecer honrados, un viejo y otro mozo.

Con lo dicho se deshizo el Campo, y salieron los de la emboscada, y se fueron todos a sus casas, digo los de la tierra, y el Capitán Vermúdez se fue a Vayona con los rehenes domingo siguiente.

Estando la armada en el puerto de Teis subieron dos lanchas, digo tres, con ciento y cincuenta hombres por la Ría arriva para saquear a Redondela, que está legua y media de allí. Sabido por [fol. 427v] los de la Villa huyeron luego, y las monjas que hay allí. Y al tiempo de entrar por la ría junto a la Villa, la mar iba baja y encallaron las lanchas, y con miedo de perderse dieron la vuelta sin hacer efecto, permitiéndolo Dios, porque si fueran, asolaran el Lugar, que será de quinientos vecinos. Las lanchas dieron la vuelta, fueron a la isla de San Simón, que está de allí medio quarto de legua con solo un Monesterio con seis frailes franciscos, los quales en aquel punto se habían metido en un barco, y quando salieron a tierra ya los escopeteaban. En efecto se escaparon y ellos fueron al Monasterio, y quebraron la campana, y la lleva-

\footnotetext{
27 Acuda (en el ms.).
} 
ron (margen $)^{28}$ y otras cosas. El Santísimo Sacramento llebó un frayle en la manga con la Custodia. Y con esto se volvieron a su armada.

A 15 del dicho, habiendo pasado lo dicho, el enemigo, no cumpliendo lo que se había trazado como hombre sin fee y sin ley, tomó junto a Vigo una nao de vacallao. Visto esto por Pedro Vermudes, le imbió a decir con Don Juan Maldonado que restituyese la riqueza de Vigo y las naos que había tomado: la respuesta fue que prendió al Dn. [fol. 428r] Juan Maldonado y a los que con él iban.

Visto esto por PedroVermudes, tornó a mandar que volviese la gente, lo qual se hizo, y a los 17 salió el enemigo del puerto de Teis, preso el Capitán Maldonado y los otros, y se pasó a las yslas de Vayona donde había estado.

Al punto nuestro Capitán repartió la gente que le había venido, por estancias para la defensa.

A 19 el enemigo tomó dos naos que venían del Brasil a la boca de las islas, y luego el mesmo día el enemigo embió a nuestro Capitán todos los que tenía presos en su nao y los rehenes, con que se holgó harto; y a él se le imbiaron los rehenes que tenía Vermúdez.

A 21 alzó velas y se fue el enemigo no se sabe a dónde, y la gente se volvió a sus casas, salvo las capitanías de soldados viejos, que esos se están en Vayona con Pedro Vermúdez, al qual S. M. hizo Capitán a guerra, y le imbió titulo.

Finis

\section{PECULIARIDADES DE LA RELACIÓN}

1.- De acuerdo con la Relación es el mismo Drake el que desembarca con sus hombres en Nuestra Señora del Burgo. A la hora de su llegada (suponemos que de la llegada de Drake) Bermúdez se retira con ciento cincuenta soldados a la fortaleza de Monte Real y deja abandonados el arrabal y la pescadería, porque los vecinos habían huido o se habían refugiado en Monte Real.

La mayoría de historiadores habla de una embajada enviada por Bermúdez en barca hacia donde se encontraba la armada, pero de la Relación se deduce que el gobernador envía la embajada desde Monte Real a Nuestra Señora del Burgo donde se encontraba Drake.

González López (1970: 288-89):

Carleill se encuentra en medio de la ría con una delegación de la villa en la que iban autoridades portuarias y un comerciante inglés para hacer la obligada visita a todo barco que llega al puerto.

\footnotetext{
28 llabe barron (en el ms.).
} 
Corbett (1970: 2) no dice quién dirigía el desembarco en el Burgo, pero sí que la embajada de Bermúdez se recibió después de llegar a tierra:

El mismo día por la tarde desembarcamos a 200 hombres justo antes de la villa, en una pequeña isla; vinieron junto a nosotros desde la villa gente de España e ingleses para saber qué queríamos. ${ }^{29}$

Harry (2002: 303) ofrece la otra versión:

Drake envía a Carleill a tierra firme, acompañado de un grupo de 700 soldados, montados en pinazas y en barcos longos; poco antes de llegar a tierra se encontraron con unos emisarios del gobernador de la localidad, quienes subieron a los botes para hablar.

Ramos (1925: 69) da los nombres del emisario principal y del comerciante inglés: «Bermúdez envía a Antonio Ruiz de Guaza para reconocer la flota junto con el comerciante inglés Roberto Skarte». Ramos también dice que el propio Drake se dirigía a tierra: «el 7 de octubre a las cuatro de la tarde salen en barca [los emisarios de Bermúdez] y encuentran a Drake, que se dirigía a tierra con 28 lanchas y 1.500 soldados».

Harry (2002: 303), pese a que dice que «Drake envía a Carleill a tierra firme, acompañado de un grupo de 700 soldados, montados en pinazas y en barcos longos» y que «poco antes de llegar a tierra se encontraron con unos emisarios del gobernador de la localidad, quienes subieron a los botes para hablar», sin embargo, después de transmitir al gobernador el mensaje de Drake, confirma su presencia en tierra:

Después de que el gobernador acordara que los barcos ingleses tenían permiso para moverse a su gusto, Drake se personó en tierra firme para comprobar que sus capitanes tenían libertad de movimiento por la zona; le informan que al día siguiente le espera el gobernador para tramitar su solicitud de compra de provisiones.

2.- La segunda peculiaridad son las mentiras o lo que en argot de jugadores llamaríamos «faroles», que se lanzan ambas partes negociadoras:

a) El número de naves de la flota de Drake: al principio de la Relación se nos dice que Drake llegó con «28 naos gruesas», pero en la embajada al gobernador le dice que, si no accede a su demanda, «con cincuenta Naos gruesas que traía, asolaría y echaría por tierra aquella Villa y Puerto».

b) El número de fuerzas de Bermúdez: la Relación dice que el gobernador «a la hora se recogió con ciento y cincuenta Soldados que tenía dentro de la Villa que se llama Monte Real», pero en la respuesta al enviado de Drake le dice que «estaba defendiendo aquella fuerza con dos mil hombres».

\footnotetext{
${ }^{29}$ La traducción de las citas de fuentes escritas en inglés es nuestra.
} 
Una circunstancia que no menciona otra versión de los hechos es la abrupta ruptura de la entrevista por parte de Bermúdez:

«Y queriendo replicar [el emisario inglés] el Capitán [Bermúdez] le mandó que no hablase más y se fuese, si no quería que le hiciese colgar de una Almena».

3.- Solo la Relación menciona el detalle anecdótico de los dos soldados ingleses que se quedaron perdidos, cuando la tropa que desembarcó en el Burgo regresó precipitadamente a la flota debido a la tormenta:

«Y con la priesa se quedaron sin poder embarcar dos mancebos Ingleses, los quales fueron hallados por la mañana entre unas peñas, y los llebaron a Pedro Bermudes».

4.- Otro aspecto que llama la atención en la Relación es la reiteración de los ofrecimientos de Bermúdez a Drake intentando granjear su benevolencia:

a) En la primera embajada le dice «que el había sabido que su Merced estaba en aquel puerto, que le suplicaba se viniese a la Villa a recibir algún servicio y regalo». Este hecho no pasa desapercibido a algún historiador inglés, que dice que Bermúdez le envió viandas a Drake ese mismo día:

Corbett (1970: 3): «el mismo día los españoles enviaron a nuestro comandante uvas, manzanas, naranjas y cosas semejantes».

Konstan (2011: 34): «el mensaje [de Bermúdez] fue acompañado por vituallas: pan, aceite y vino, un regalo del pueblo de Galicia, intento obvio de aplacar al inglés».

b) En su respuesta al emisario de Drake vuelve a insistir «que le suplicaba otra ves viniese a aquella Villa a recibir servicio y regalo».

c) Después del enfrentamiento entre tropas de ambas partes en el valle de Teis, es también Bermúdez el que toma la iniciativa de parlamentar:

Se puso a la orilla del Puerto donde estaba la Armada. Luego imbió recaudo al enemigo diciendo que él estaba allí, y que quería saber dél qué era lo que pretendía o quería más de lo que había dicho.

Los historiadores ingleses dan versiones muy distintas del hecho: alguno insinúa que el gobernador, a la vista de la inferioridad de sus fuerzas, decide parlamentar una tregua:

Keeler (1981: 85):

Antes habían desembarcado un número de hombres de los barcos que llevaban allí toda la noche y se produjeron escaramuzas en las que los españoles perdieron 4 hombres y los ingleses uno solo, por lo que el gobernador desconfiando de sus fuerzas envió mensajeros para parlamentar con el general. 
Ese matiz también parece desprenderse de la Relación cuando dice de esa entrevista Bermúdez-Drake:

Y que en lo que él [Drake] pretendía de que se restituyese a la Reyna de Ingalaterra sus vasallos y haciendas, que pues aquello no se podía hacer sin orden de S. M.; que en el entretanto que se le diese $\mathrm{p}<$ arte $>$ y escribiese a la Reyna de Yngalaterra, no haría daño con su armada en este puerto ni Reyno.

De esta tregua la Relación no menciona la parte que correspondía cumplir a los españoles, detalle que no escapa a los historiadores ingleses, llegando a afirmar alguno de ellos que no se sabe si Drake cumplió lo pactado de devolver todo lo robado en Vigo:

Harry (2002: 307):

Al día siguiente al ataque el gobernador envió una delegación a Drake solicitando la celebración de una reunión, en la que se fijaron las condiciones: se permitiría a los ingleses comerciar y hacer aguada; se pondría en libertad a los comerciantes ingleses que estuvieran encarcelados. En contrapartida: los asaltantes ingleses se comprometían al pago de los bienes saqueados. Las dos primeras disposiciones se cumplieron, pero no hay constancia de la indemnización o pago de los bienes robados.

Tampoco la Relación hace la más mínima mención a la devolución efectiva de lo robado por los ingleses, pese a la insistencia en recalcarla como parte del pacto de tregua.

Otro historiador inglés dice que los soldados ingleses se abastecieron de todo lo necesario y paseaban a sus anchas por la villa, confiados en la potencia de los cañones de su armada:

Konstan (2011: 34):

La flota permaneció alejada del puerto durante la mayor parte de dos semanas y los marineros ingleses paseaban descaradamente por las calles, protegidos por el poder de fuego de los navíos de Drake.

También mencionan visitas de los vecinos a la armada para comer con ellos:

Corbett (1970: 4): «el día siguiente, 3 de octubre, vinieron españoles a bordo de nuestra nave Almirante a comer con nosotros».

Keeler (1981: 87):

Domingo, 3 de octubre: este día muchos españoles vinieron a bordo de nuestros barcos y de igual manera nuestros hombres fueron a la orilla y se aprovisionaron de agua.

5.- Los enfrentamientos en la zona de Teis: la Relación se detiene con cierto regusto en la descripción del enfrentamiento singular de un soldado español y otro inglés, relato que no aparece en ninguna otra versión de las que hemos consultado: 
Y un Soldado de los nuestros viéndose con uno rostro a rostro, encararon los Arcabuces y no tomaron lumbre, y con las Espadas se afirmaron, y el nuestro pasó de una estocada a su contrario, y con el cuchillo de la vayna se puso encima dél, y le cortó la cabeza, y estándosela cortando los enemigos de las Lanchas le tiraron al nuestro muchos cañonazos, mas plugo a Dios que no le acertaron, y en la punta del cuchillo trajo la Cabeza a Vigo, y el Capitán le señaló de ventaja seis escudos.

La versión de Harry (2002: 306) no parece concordar con la Relación, pues en el asalto a Vigo y sus alrededores dice que no encontraron resistencia:

Como la mayoría de la población había huido, no encontraron gran oposición, aunque se produjo la baja de un marinero inglés que casualmente entró en el puerto y lo sorprendieron robando una casa y entre varios habitantes lo estrangularon y le cortaron la cabeza.

Parecida es la versión de Keeler (1981: 86):

También hubo un joven marinero que se separó de sus compañeros para el pillaje y fue sorprendido por los habitantes, que le cortaron la cabeza.

6.- Tampoco hay constancia en el resto de fuentes de la emboscada que las tropas españolas prepararon sigilosamente a altas horas de la noche:

Estando junta la armada enemiga en el puerto de Teis, y nuestro Capitán en Vigo con toda su gente, que serían cinco mil hombres bien puestos, se dio orden de componerlos; y a once del presente, ya a las dos de la noche, a la orilla del mar en una montañeta frontera del enemigo, sin ser sentidos se embarcaron ciento y ochenta arcabuceros y mosqueteros de la compañía de Don Diego de Córdova, y de la gente de Don García Sarmiento.

7.- El saqueo de Redondela y la isla de San Simón, cuando ya se habían retirado las tropas por la tregua, tampoco es mencionado por las fuentes consultadas, ni españolas ni inglesas. Ambas acciones se vieron frustradas por las circunstancias, pero dieron motivo a Bermúdez para volver a convocar a todas sus fuerzas y quizá a motivar la partida de la flota corsaria:

Estando la Armada en el puerto de Teis subieron dos Lanchas, digo tres, con ciento y cincuenta hombres por la Ría arriva para saquear a Redondela, que está legua y media de allí. Sabido por los de la Villa huyeron luego, y las Monjas que hay allí. Y al tiempo de entrar por la ría junto a la Villa, la mar iba baja y encallaron las Lanchas, y con miedo de perderse dieron la vuelta sin hacer efecto, permitiéndolo Dios, porque, si fueran, asolaran el Lugar, que será de quinientos vecinos.

Las Lanchas dieron la vuelta, fueron a la Isla de San Simón, que está de allí medio quarto de legua con solo un Monesterio con seis frailes franciscos, los quales en aquel punto se habían metido en un Barco, y quando salieron a tierra ya los escopeteaban: en efecto se escaparon y ellos fueron al Monasterio, y quebraron la Campana, y la llevaron y otras cosas. El 
Santísimo Sacramento llebó un frayle en la manga con la Custodia. Y con esto se volvieron a su Armada.

8.- Tampoco figura en otras fuentes la captura del capitán Maldonado por parte de Drake, cuando, tras el ataque a Redondela, Bermúdez lo envía para quejarse por su actuación contraria a lo pactado:

A 15 del dicho habiendo pasado lo dicho, el enemigo, no cumpliendo lo que se había trazado, como hombre sin fee y sin ley, tomó junto a Vigo una Nao de Vacallao. Visto esto por Pedro Vermudes le imbió a decir con Don Juan Maldonado, que restituyese la riqueza de Vigo, y las naos que había tomado: la respuesta fue que prendió al Don Juan Maldonado y a los que con él iban.

9.- La Relación silencia prácticamente los días que precedieron a la marcha de la flota y el canje de rehenes, pero las fuentes inglesas dejan claro que hubo dificultades en la negociación:

Corbett (1970: 4-5) menciona que hubo dificultades en la negociación del canje:

El día 6 fuimos a un fondeadero antes de Vigo nuevamente y enviamos a la orilla para traer a nuestros capitanes a bordo, pero ellos lo retrasaban y enviaban más españoles a bordo nuestro, y allí hubo conversaciones entre los españoles de que si nos retrasábamos allí 16 días, ellos lavarían sus manos en sangre de ingleses.

Finalmente se llega a un acuerdo y se intercambian los rehenes:

El día 8 preparamos tres pinazas, una galera y el navío George y los enviamos a Bayona, donde después de mucho parlamento recibimos a nuestros capitanes y les entregamos sus hombres.

Keeler (1981: 89):

Sábado día 9: esa mañana el capitán Frobisher y otro capitán fueron enviados a Bayona con tres pinazas y con ellos los rehenes españoles que ellos debían pedir y traer a bordo nuestros rehenes y entregar los españoles; el propio gobernador acudió con los rehenes ingleses y asistió al intercambio de ambos bandos.

El despliegue de navíos sugiere algo de intimidación por parte de los ingleses. ¿Podría pensarse que Drake no cumplió lo pactado y no devolvió lo que había robado (de ahí el tira y afloja en la negociación), pero que, pese a ello, el gobernador Bermúdez respiraría más tranquilo al facilitar la partida de enemigo tan fuerte y peligroso?

Algunos historiadores, como Konstan (2011: 34), reflexionan sobre el dilema que se le presentó a Bermúdez en su actuación:

Cuando la flota de Drake finalmente zarpó de Vigo el 11 de octubre, D. Pedro Bermúdez debió sentirse un hombre aliviado, pero todavía tiene que responder por sus actos ante el rey. Después de todo, Drake ha dicta- 
do sus condiciones en suelo español y chantajeado la provisión de vituallas virtualmente a punta de pistola. Los ataques a las colonias españolas eran una cosa, pero semejantes incidentes en la misma España eran considerados como un grave insulto, una humillación internacional. Peor aún, el español no tenía idea de a dónde iba Drake después.

Nada de esto refleja la Relación, que concluye su relato quizá como el final feliz de una pesadilla:

A 21 alzó velas y se fue el enemigo no se sabe a dónde, y la gente se volvió a sus casas, salvo las capitanías de soldados viejos, que esos se están en Vayona con Pedro Vermúdez, al qual S. M. hizo Capitán a guerra, y le imbió título. Finis.

\section{BIBLIOGRAFÍA}

Álvarez Blázquez, X. M. (2008) A cidade e os dias, Calendario histórico de Vigo, Edicions Xerais, Vigo, (reed. de 1960, ed. Monterrei), pp. 427-429.

Biblioteca Nacional: Inventario general de manuscritos de la biblioteca nacional, vol. XII, Madrid, 1987.

Corbett, J. S. (1970) Papers relating to the navy during The Spanish War 15851587, New York, [1898], pp. 1 - 5.

Fernández De La Cigoña Fraga, S. (2008) Crónicas y estampas de Baiona la Real, ed. Diputación Provincial de Pontevedra, pp. 98-101.

González López, E. (1970) «Drake en la ría de Vigo», Revista Grial, n 29, pp. 285-293.

González López, E. (1980) La Galicia de los Austrias, Galicia Histórica, t. I, ed. Fundación Pedro Barrié de la Maza, A Coruña, pp. 297-303.

Harry, K. (2002) Sir Francis Drake. El pirata de la reina, Barcelona, pp. 302307.

Keeler, M. F. (1981) Sir Francis Drake's West Indian voyage, 1585-86, London, pp. 77-89.

Konstan, A. (2011) The great expedition: Sir Francis Drake on the Spanish Main, 1585-1586, New York, pp. 27- 35.

Miguélez, M. F. (1917) Catálogo de los Códices españoles de la Biblioteca del Escorial, I, Madrid.

Lloyd, Ch. (1958) Drake, corsario y almirante, Madrid, pp. 98-100.

Ramos González, H. (1925) Crónicas históricas de la villa de Bayona, Madrid, pp. 68-72. 
